\title{
Pattern of Thyroid Disease in Hail Region, Saudi Arabia
}

\author{
Dr. Safia Moussa ${ }^{1}$ Amal Alshammari ${ }^{2}$, Gada Alshammari ${ }^{3}$, Kawther Alshammar ${ }^{4}$ Maram Alanzi $^{5}$, \\ Nadia Alanzi ${ }^{6}$, Zainab Alshammari ${ }^{7}$ \\ ${ }^{1}$ Professor in Microbiology and Parasitology Department, University of Hail, College of Medicine, Hail, Saudi Arabia . \\ 2, 3, 4, 5, 6, 7 Internship doctors , University of Hail, College of Medicine, Hail, Saudi Arabia
}

\begin{abstract}
Background: Thyroid gland is one of the important organ in human body and the burden of thyroid diseases in the general population is enormous specially in females. In Saudi Arabia its pattern is differ from area to area. Aim of the study: The present work was conducted to study the pattern of thyroid disorders among patients attended to the endocrinology clinics in King Khalid Hospital, Hail region, Saudi Arabia. Results: The patients complaining of different thyroid disorders were 175. 98(56\%) cases was found to have hypothyroidism and 57 (32.6 \%) had hyperthyroidism. Iodine deficiency was associated with hypothyroidism in females but it was common in males with hyperthyroidism. The etiology and risk factors of hypothyroidism were stress, malignant tumors, Hashimooto thyroiditis and diabetes in males while they were bad nutrition, Iodine deficiency, goiter, benign thyroid tumor and family history in females. Diabetes, graves, disease, benign and malignant tumors were common in males but bad nutrition, iodine deficiency, goiter and family history were the more frequent in fameless suffered from hyperthyroidism.Total cases with goiter were 89 most of them were males (60.7\%) palpable goiter was more common 75.5 than visible type. Malignant thyroid were found mainly in males (75\%) with papillary type of cancer (64.3\%) and the common presenting manifestation was hyperthyroidism (53.6\%). Conclusion: Thyroid disorders are common in Hail region specially in females. The pattern is more or less similar to that detected in other Saudi cities .Goiter and malignant thyroid are more common in males. Recommendation: More studies should be carried out in Hail region to stress on the individual thyroid disorder so as more comprehensive studies could be obtained.
\end{abstract}

Keywords: Pattern, thyroid diseases, Hail, Saudi Arabia

\section{Introduction}

Thyroid gland is one of the important organ in human body and the burden of thyroid diseases in the general population is enormous specially in females. Thyroid disorders create many problems although most undergo medical or surgical management. Thyroid diseases are generally grouped and manifested into two main categories which are either due to reduced activity of the gland (hypothyroidism) or due to over activity (hyperthyroidism). The former are more common in older people (La Franchi, 1994\& Griffith et al 1999).

The epidemiology of thyroid diseases in iodine- sufficient areas deals mainly with sporadic goiter and thyroid autoimmune diseases (Elahi et al 2005). However in iodine deficient areas, other kind of goiters and thyroid cancers are more prevalent. The incidence of Multinodular goiter differs according to the countries and seems to be widely dependant on the iodine status( Abu-Eshy et al 1994)

The forms of thyroid disorders include nontoxic goiter, Graves 'disease, Hashimoto's thyroiditis and thyroid neoplasm (Rallison et al.1991). There are two main important autoimmune thyroid disorders which are Hashimoto thyroiditis and Graves disease. The former is the most common cause of hypothyroidism, whereas the latter is a major cause of hyperthyroidism (Rossi et al., 1985). There is a well known geographical dependency in thyroid diseases because of the different amounts of alimentary iodine intake that occur in different geographic locations (Knudsen et al., 2000). The number of people in the community who have microscopic nodules, palpable goiter, and occult papillary carcinoma has to be considered
Risk factors of thyroid disease include: Gender (thyroid disorders are higher in women than in men), Diet rich in goitrogens or deficient in iodine, Pregnancy, Radiation to the neck , Family history and Smoking (Abdul Rahman et al 1997 )

The incidence and pattern of thyroid diseases were studied in Saudi Arabia by some investigators (Al-Tameem, 1987; Koriesh et al., 1988; Abu-Eshy et al., 1994; Al-Zahrani et al., 2005). However little is known about thyroid disorder studies in Hail area, so the present study was undertaken study the pattern and problem of disorders among patients attended the outpatient clinic of endocrinology , Hail area, Saudi Arabia.

\section{Patients and Methods}

This is retrospective study included 175 patients with thyroid diseases attended the endocrine outpatient clinic of King Khalid hospital, Saudi Arabia during the year 2013. They were clinically diagnosed as having thyroid disorders. They were represented either by manifestation of hypothyroidism, hyperthyroidism or enlargement of thyroid gland. The data were collected from the medical admission and outpatients records. The data included sociodemographic data, clinical presentation, causes and risk factors .Results were tabulated and analyzed

\section{Results}

The total number of patients attended the endocrinology clinic in King Khalid hospital was 819. The patients complaining of different thyroid disorders were 175 (21.4\%) 


\section{International Journal of Science and Research (IJSR) \\ ISSN (Online): 2319-7064 \\ Index Copernicus Value (2013): 6.14 | Impact Factor (2014): 5.611}

. Table (1) represented the age distribution of the subjects according to thyroid dysfunction. The mean age of the patients was 42 years. The results of the current work demonstrated that out of 175 patients, 98 cases $(27$ male and 71 female ) was found to have hypothyroidism and 57 (26 male and 31 female) have hyperthyroidism (Table 2).

Stress (59.4\%), malignant tumors (75\%), Hashimooto thyroiditis $(75.6 \%)$, and DM $(70.6 \%)$ as risk factors of hypothyroidism were more prevalent in males than females. While bad nutrition $(89.8 \%)$, Iodine deficiency (87.2), goiter $(51.6 \%)$, benign thyroid tumor (84.4) and family history $(80.8 \%)$ were more prevalent in females with hypothyroidism.

Iodine deficiency was associated with hypothyroidism in females but it was common in males with hyperthyroidism.

Concerning hyperthyroidism, stress, DM, graves disease, benign and malignant tumors were the common risk factors in males. Moreover, bad nutrition, iodine deficiency, goiter and family history were the more frequent in fameless.

Table (5)revealed that palpable goiter was more common 75.5than visible type and it was more prevalent in males $(60.7 \%)$ (table 6$)$. Total cases with goiter was (89)

Subjects with thyroid swelling (goiter $=89$ cases) in the current study were represented either by diffuse type ( 41 cases) or solitary nodular type (38 cases ) . The histopathological studies obtained from the patients files revealed that 30 cases out of the 38 case with solitary nodules were benign

As regarding thyroid cancer, patients with thyroid cancer in the current study were mainly males $(75 \%)$ with papillary type of cancer $(64.3 \%)$ and the common presenting manifestation was hyperthyroidism (53.6\%).(tables 7,8,9)

The most common manifestation in Patients complaining of hypothyroidism in the present work was obesity $(65.3 \%)$. Whereas it was palpitation in case of hyperthyroidism $(87.7 \%)$ Table $(10,11)$

Table 1: Age distribution in relation to thyroid dysfunction among patients with thyroid disorders in King Khalid Hospital, Hail region, Saudi Arabia during the year of 2013.

\begin{tabular}{|c|c|c|c|c|c|}
\hline \multirow{2}{*}{$\begin{array}{c}\text { Age } \\
\text { categories }\end{array}$} & \multicolumn{2}{|c|}{ Hypothyroidism } & \multicolumn{2}{|c|}{ Hyperthyroidism } & \multirow{2}{*}{$\begin{array}{l}\text { Total } \\
\text { cases }\end{array}$} \\
\hline & number & $\%$ & number & $\%$ & \\
\hline 0-10 years & 7 & 7.1 & 0 & 0 & 7 \\
\hline $10-20$ years & 8 & 8.2 & 5 & 8.8 & 13 \\
\hline 20-30 years & 16 & 16.3 & 10 & 17.5 & 26 \\
\hline 30-40 years & 21 & 21.4 & 13 & 22.8 & 34 \\
\hline 40-50 years & 28 & 28.6 & 12 & 21.1 & 40 \\
\hline$>50$ years & 39 & 39.8 & 16 & 28.1 & 55 \\
\hline Total & 98 & 56 & 57 & 32.6 & 175 \\
\hline
\end{tabular}

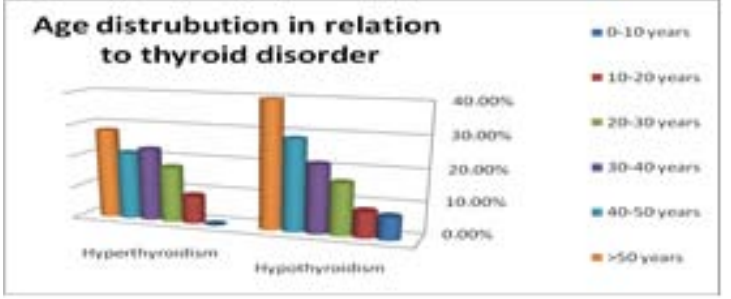

Table 2: Sex distribution in relation to thyroid dysfunction among patients with thyroid disorders in King Khalid Hospital, Hail region, Saudi Arabia during the year of 2013.

\begin{tabular}{|c|c|c|c|c|c|}
\hline \multirow{2}{*}{ Disorder } & \multicolumn{2}{|c|}{ Female } & \multicolumn{2}{c|}{ Male } & Total \\
\cline { 2 - 5 } & number & $\%$ & number & $\%$ & \\
\hline $\begin{array}{c}\text { Patients with } \\
\text { hypothyroidism }\end{array}$ & 71 & $72.4 \%$ & 27 & $27.6 \%$ & 98 \\
\hline $\begin{array}{c}\text { Patients with } \\
\text { Hyperthyroidism }\end{array}$ & 31 & $54.4 \%$ & 26 & $45.6 \%$ & 57 \\
\hline
\end{tabular}

\section{Sex distribution in relation to thyroid disorders}

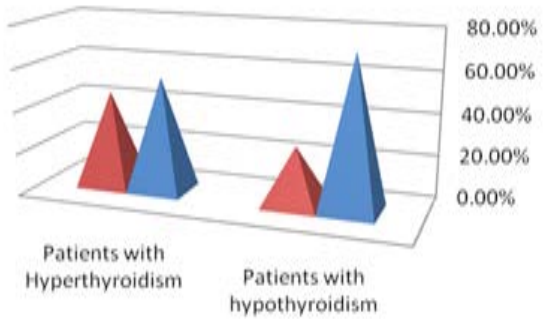

a Female

Male

Table 3: Etiology and risk factors of hyperthyroidism among patients with thyroid disorders in King Khalid Hospital, Hail region, Saudi Arabia during the year of 2013.

\begin{tabular}{|c|c|c|c|c|c|}
\hline \multirow{2}{*}{} & \multicolumn{2}{|c|}{ Males } & \multicolumn{2}{c|}{ Females } & \multirow{2}{*}{ Total } \\
\cline { 2 - 5 } & Number & $\%$ & number & $\%$ & \\
\hline Stress & 24 & $72.7 \%$ & 9 & $27.3 \%$ & 33 \\
\hline Bad nutrition & 6 & $13.3 \%$ & 39 & $86.7 \%$ & 45 \\
\hline DM & 32 & $76.1 \%$ & 10 & $23.8 \%$ & 42 \\
\hline Iodine deficiency & 33 & $84.6 \%$ & 6 & $15.3 \%$ & 39 \\
\hline \multicolumn{7}{|c|}{ Etiology } \\
\hline Goiter & 3 & $11.1 \%$ & 24 & $88.9 \%$ & 27 \\
\hline Graves' disease & 28 & $66.7 \%$ & 14 & $33.3 \%$ & 42 \\
\hline Benign neoplasm & 28 & $73.7 \%$ & 10 & $26.3 \%$ & 38 \\
\hline Malignant neoplasm & 12 & $80.0 \%$ & 3 & $20 \%$ & 15 \\
\hline Family history & 2 & $13.3 \%$ & 13 & $86.6 \%$ & 15 \\
\hline
\end{tabular}




\section{International Journal of Science and Research (IJSR) \\ ISSN (Online): 2319-7064}

Index Copernicus Value (2013): 6.14 | Impact Factor (2014): 5.611

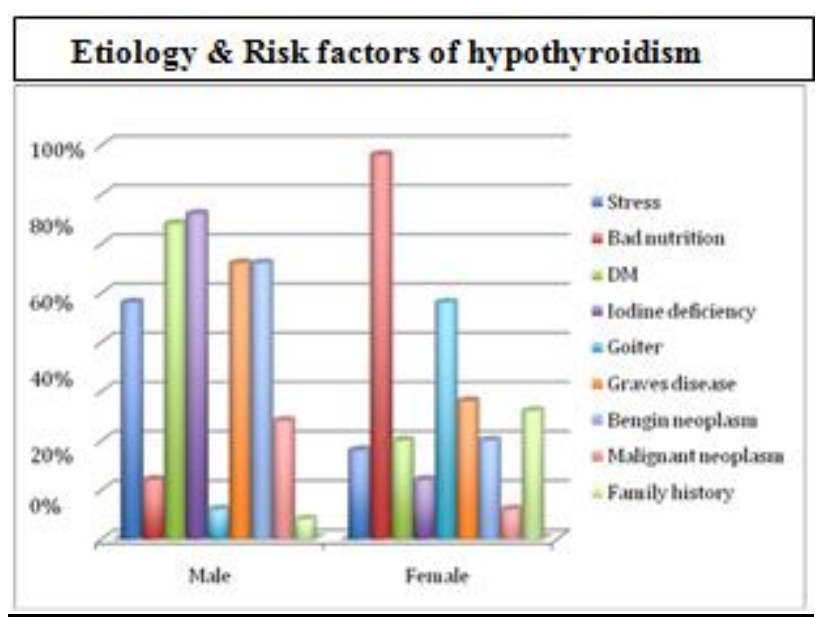

Table 4: Etiology and risk factors of hypothyroidism among patients with thyroid disorders in King Khalid Hospital, Hail region, Saudi Arabia during the year of 2013.

\begin{tabular}{|c|c|c|c|c|c|}
\hline & \multicolumn{3}{|l|}{ Female } & \multicolumn{1}{l|}{ Male } & Total \\
& \multicolumn{7}{|c|}{ cases } \\
\cline { 2 - 6 } & Ro $\%$ & \multicolumn{1}{l|}{ No } & $\%$ & \\
\hline Stress & 13 & 40.6 & 19 & 59.4 & 32 \\
\hline Pregnancy & 57 & 100 & - & - & 57 \\
\hline Bad nutrition & 53 & 89.8 & 6 & 10.2 & 59 \\
\hline DM & 15 & 29.4 & 36 & 70.6 & 51 \\
\hline Iodine deficiency & 41 & 87.2 & 6 & 12.8 & 47 \\
\hline \multicolumn{7}{|c}{ Etiology } \\
\hline Goiter & 32 & 51.6 & 30 & 48.4 & 62 \\
\hline Hashimoto thyroiditis & 10 & 24.4 & 31 & 75.6 & 41 \\
\hline Benign & 43 & 84.3 & 8 & 15.7 & 51 \\
\hline Malignant & 4 & 30.8 & 9 & 69.2 & 13 \\
\hline Family history & 59 & 80.8 & 14 & 19.2 & 73 \\
\hline Radiation & 1 & 50 & 1 & 50 & 2 \\
\hline Congenital & 1 & 33.3 & 2 & 66.6 & 3 \\
\hline
\end{tabular}

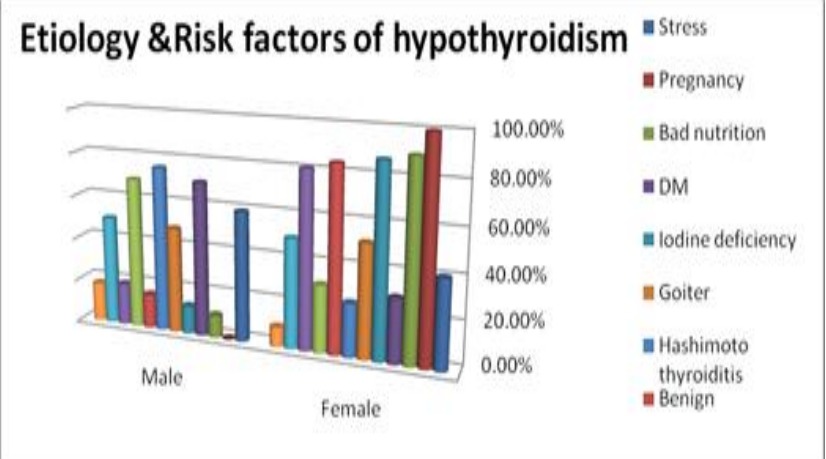

Table 5: Classification of goiter in relation to thyroid dysfunction among patients with thyroid disorders in King Khalid Hospital , Hail region, Saudi Arabia during the year of 2013 .

\begin{tabular}{|c|c|c|c|c|c|}
\hline Goiter & \multicolumn{2}{|c|}{ Hyperthyroidism } & \multicolumn{2}{|c|}{ Hypothyroidism } & $\begin{array}{c}\text { Number of } \\
\text { patient with } \\
\text { goiter }\end{array}$ \\
\cline { 3 - 6 } & number & $\%$ & number & $\%$ & 40 \\
\hline Visible goiter & 15 & 37.5 & 25 & 62.5 & 49 \\
\hline Palpable goiter & 12 & 24.5 & 37 & 75.5 & 89 \\
\hline Total & 27 & 30.3 & 62 & 69.7 & \\
\hline
\end{tabular}

\section{Pattern of goiter}

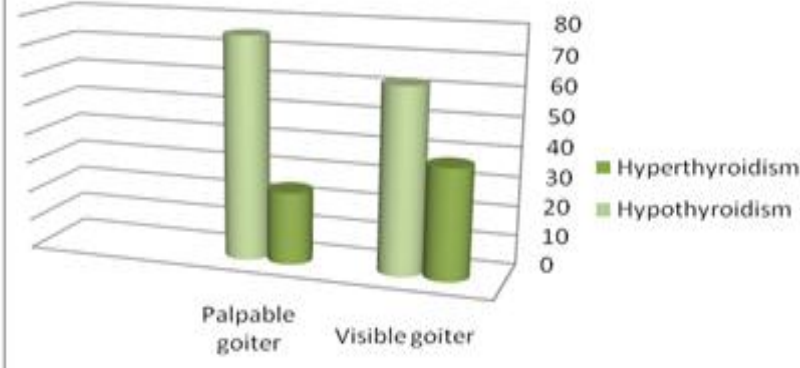

Table 6: Classification of goiter in relation to sex among patients with thyroid disorders in King Khalid Hospital, Hail region, Saudi Arabia during the year of 2013.

\begin{tabular}{|c|c|c|}
\hline \multirow{2}{*}{ Goiter in relation to sex } & \multicolumn{2}{|c|}{ Patients } \\
\cline { 2 - 3 } & Number & $\%$ \\
\hline Male & 54 & 60.7 \\
\hline Female & 35 & 39.3 \\
\hline Total & 89 & 100 \\
\hline
\end{tabular}

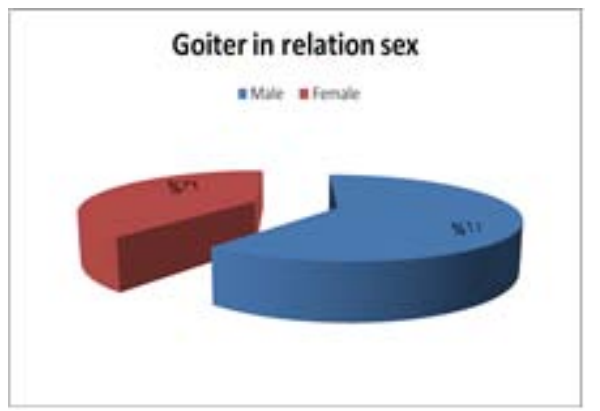

Table 7: Pattern of thyroid carcinoma among patients with thyroid disorders in King Khalid Hospital, Hail region,

Saudi Arabia during the year of 2013.

\begin{tabular}{|c|c|c|}
\hline $\begin{array}{c}\text { Pattern of } \\
\text { thyroid } \\
\text { carcinoma }\end{array}$ & \multicolumn{2}{|c|}{$\begin{array}{c}\text { Patients with } \\
\text { thyroid } \\
\text { carcinoma }\end{array}$} \\
\cline { 2 - 3 } & Number & $\%$ \\
\hline Papillary & 18 & 64.3 \\
\hline Follicular & 3 & 10.7 \\
\hline Medullary & 4 & 14.3 \\
\hline Undifferentiated & 2 & 7.1 \\
\hline Metastatic & 1 & 3.6 \\
\hline Total & 28 & 100 \\
\hline
\end{tabular}

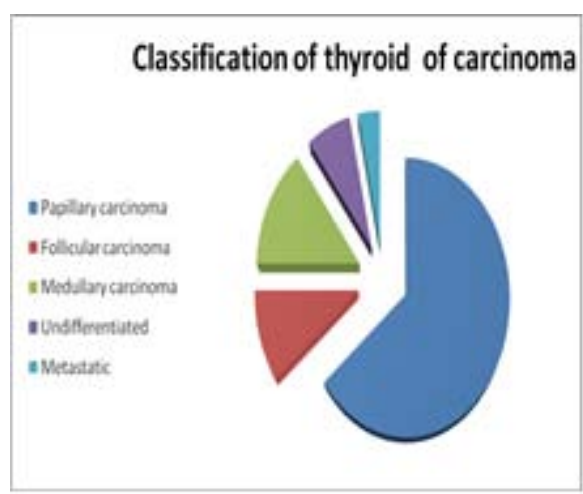




\section{International Journal of Science and Research (IJSR) \\ ISSN (Online): 2319-7064}

Index Copernicus Value (2013): 6.14 | Impact Factor (2014): 5.611

Table 8: Pattern of thyroid carcinoma in relation to sex among patients with thyroid disorders in King Khalid Hospital, Hail region, Saudi Arabia during the year of 2013.

\begin{tabular}{|c|c|c|}
\hline Pattern of carcinoma & \multicolumn{2}{|c|}{ Patients } \\
\cline { 2 - 3 } according to sex & Number & $\%$ \\
\hline Males & 21 & 75 \\
\hline Females & 7 & 25 \\
\hline Total & 28 & 100 \\
\hline
\end{tabular}

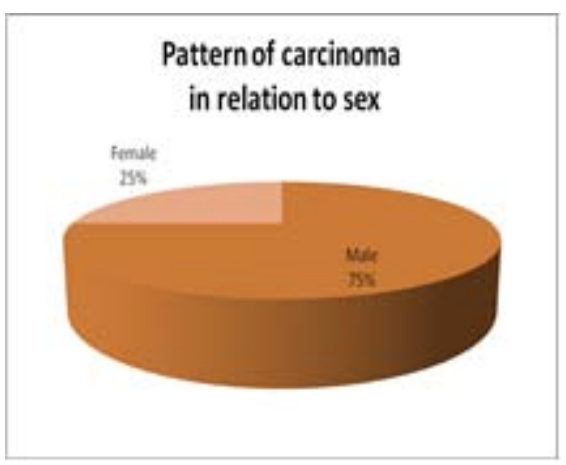

Table 9: Pattern of thyroid carcinoma in relation to thyroid dysfunction among patients with thyroid disorders in King Khalid Hospital, Hail region, Saudi Arabia during the year of 2013 .

\begin{tabular}{|l|l|l|}
\hline \multirow{2}{*}{ Pattern of carcinoma } & \multicolumn{2}{|c|}{ Patients } \\
\cline { 2 - 3 } & Number & $\%$ \\
\hline Hypothyroidism & 13 & 46.4 \\
\hline Hyperthyroidism & 15 & 53.6 \\
\hline Total & 28 & 100 \\
\hline
\end{tabular}

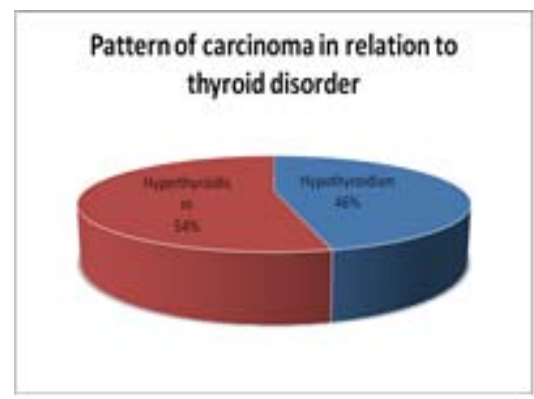

Table (10) clinical manifestation of hypothyroidism among patients with thyroid disorders in King Khalid Hospital, Hail region, Saudi Arabia during the year of 2013

\begin{tabular}{|c|c|c|}
\hline Clinical manifestation & \multicolumn{2}{|c|}{ Patients } \\
\cline { 2 - 3 } & Number & $\%$ \\
\hline Fatigue & 42 & $42.8 \%$ \\
\hline Constipation & 49 & $50 \%$ \\
\hline Hoarse voice & 32 & $32.6 \%$ \\
\hline Dry skin & 27 & $27.5 \%$ \\
\hline Cold & 30 & $30.6 \%$ \\
\hline Goiter & 28 & $28.5 \%$ \\
\hline Obesity & 64 & 65.3 \\
\hline
\end{tabular}

\section{Clinical manifestation of hypothyroidism}

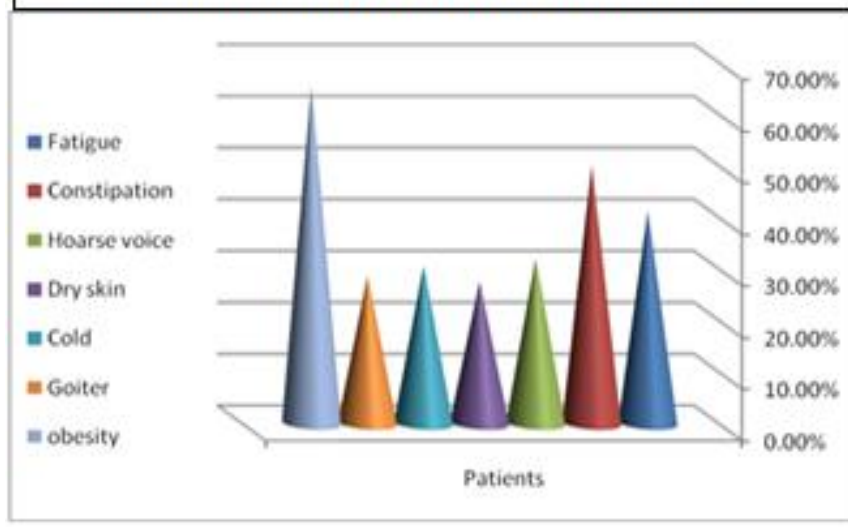

Table 11: clinical manifestation of hyperthyroidism among patients with thyroid disorders in King Khalid Hospital, Hail region, Saudi Arabia during the year of 2013.

\begin{tabular}{|l|l|l|}
\hline \multirow{2}{*}{ Clinical manifestation } & \multicolumn{2}{|c|}{ Patient } \\
\cline { 2 - 3 } & number & $\%$ \\
\hline Palpitation & 50 & 87.7 \\
\hline Tremors & 36 & 63.2 \\
\hline Weight loss & 28 & 49.1 \\
\hline Sweating & 20 & 35.1 \\
\hline Heat intolerance & 13 & 22.8 \\
\hline Nervousness & 19 & 33.3 \\
\hline Fatigue & 9 & 15.7 \\
\hline Exophthalmos & 22 & 38.6 \\
\hline Goiter & 15 & 26.3 \\
\hline Anxiety & 15 & 26.3 \\
\hline Irritability & 6 & 10.6 \\
\hline Tremors & 22 & 38.6 \\
\hline Total & 57 & 100 \\
\hline
\end{tabular}

Total number of patients with hxperthvroidism. 57.

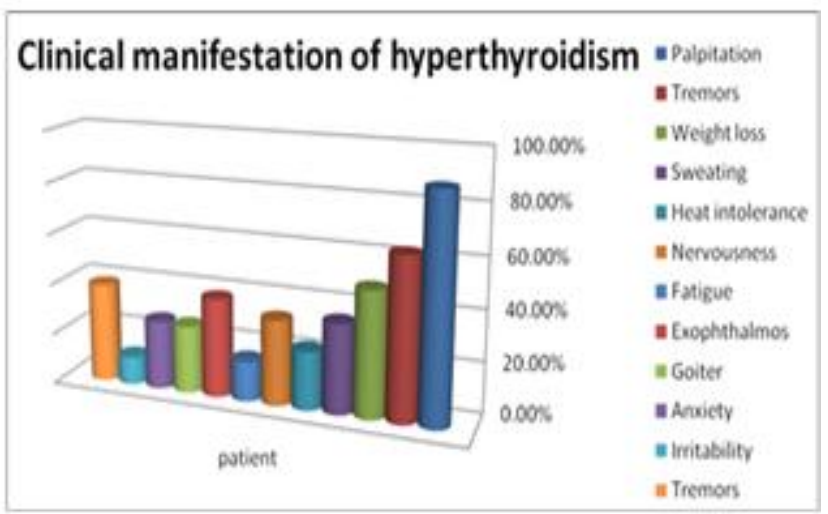

Diseases of the thyroid are of great importance because most are amenable to medical or surgical management. Patients with thyroid diseases usually presented by conditions associated with excessive release of thyroid hormones (hyperthyroidism), deficiency of the hormone hypothyroidism), and mass lesions of the thyroid (Maitra et al ;2008)

Risk factors of thyroid disease include: Gender, Diet rich in goitrogens or deficient in iodine, Pregnancy, Radiation to the neck , Family history and Smoking (Marita et al , 2008) 


\section{International Journal of Science and Research (IJSR) \\ ISSN (Online): 2319-7064 \\ Index Copernicus Value (2013): 6.14 | Impact Factor (2014): 5.611}

Hypothyroidism results from deficient production of the thyroid hormone or defects in thyroid hormone receptor activity. The disorder may be acquired or congenital manifested at birth or delayed as a result of a variety of congenital defects. Congenital causes of hypothyroidism may be sporadic or familial (Ordookhani et al., 2005).

The current study revealed that out of 175 patients , 98 cases ( 27 male and 71 female ) was found to have hypothyroidism and 57 (26 male and 31 female) had hyperthyroidism likewise, it was documented by many authors that hypothyroidism is more common in females while hyperthyroidism is more common in males ( Martin ; 2013.) In addition stress (59.4\%), malignant tumors ( $75 \%$ ), Hashimootothyroidiis, and DM as risk factors of hypothyroidism were more prevalent in males than females. While the common risk factors in females were bad nutrition, iodine deficiency, goiter, benign thyroid tumor and family history were more prevalent in females with hypothyroidism comparable with males (Wang et al ;1997 \& Morganti et al ; 2005)

Similarly, Flynn et al; 2004 reported that conditions such as bad nutrition and poorly controlled diabetes were among causes of hypothyroidism in females. Our results on the contrarily revealed that the uncontrolled DM was found as a risk factor in males .Akbar et al. 2006 as well as our study reported that family history of hypothyroidism is associated with an increase risk and the role of familial susceptibility to thyroid disorders was highly related . Congenital hypothyroidism in the current work increased significantly in males $(18 \%)$ than in females $(9 \%)$ which is in consistent with the study of Wintergerst et al (Wintergerst et al ;2014)

Concerning hyperthyroidism, stress, DM, graves disease, benign and malignant tumors were common in males. Moreover, bad nutrition, iodine deficiency, goiter, family history and radiation were the more frequent in females. Likewise same results were obtained by Abdul Shakoor et al while other authors didn't find relation with family history to thyroid diseases (Abdul Shakoor et al 2014)

Iodine deficiency was associated with hypothyroidism in females but it was common in males with hyperthyroidism likewise high iodine deficiency was recorded in hypothyroidism females and hyperthyroidism males. Epidemiological studies has shown that pattern of thyroid dysfunction in a community is largely determined by iodine intake level (Knudsen et al. 2000). Kutras (2001) reported that iodine deficiency, thyroid autoimmunity, infection and previous irradiation are the common etiological factors of thyroid disorders In iodine deficient communities incidence of hypothyroidism is low while nontoxic goiter and hyperthyroidism due to toxic nodular goiter is common and increases with age. Like the results of the present study, high incidence of Hashimoto thyroidits was recorded in hypothyroidism males. Hanna and LaFranchi (2002) reported that thyroid autoimmune diseases like Graves' disease and Hashimoto's thyroditis are common reason of thyroid diseases. Takasu et al. (1990) described eight cases of autoimmune thyroid disease with an alternating pattern of thyroid function.
Goiter in the present study was found to be higher in males $(60.7 \%)$ than in females $(39.3 \%)$. On the other hands Elhai et al (2005) reported an incidence of $60.6 \%$ in females. This may be due to the kind of their patients which were referred from a centre for nuclear medicine. On the contrarily one again, Al-Bouq et al. (2006) reported that the incidence of goiter was much less than that of ours $(19.6 \%)$ in MedinahMunawarah, Saudi Arabia. A high incidence of goiter was also recorded in Gizan,Saudi Arabia (Sulimani et al. 1995), Bombay, India (Dodd and Samul ,1993) and Tunisia (El-May et al.1997). The appearance of goiter depends on many factors like sex, family history, iodine intake and thyroid autoimmunity. Low iodine intake enhances the TSH sensitivity and positive influence of growth factors involved in the physiological regulation of thyroid growth.

In Saudi Arabia thyroid cancer is the fourth most common cancer in all age and the second most common cancer in female ( National Cancer Registry ;1997).

The number of cases with malignant thyroid in the current study among cases admitted to the endocrinology clinic was $28 \quad(12.9 \%$ and $9.2 \%$ in hypothyroidism and hyperthyroidism, respectively. It was reported that incidence of malignant thyroid varies from one geographical area to the other. It was recorded as $13 \%$ in Asir, (Abu-Eshy et al ; 1994) and $21 \%$ in Riyadh (Al-Tameem , 1987) There are different causal factors of malignant thyroid such as prolonged high level of TSH and iodine deficiency (Belfiore et al.1992).

Papillary carcinoma in the present work was the most common histological subtype $(64.3 \%)$ followed by medullary carcinoma $(14.3 \%)$, then follicular variant $(10.7 \%)$.The least was the undifferentiated $(7.1 \%)$. In a retrospective study done by Hussain et al ; 2013 during the year of 2000-2010 to investigate the Incidence of thyroid cancer in the Kingdom of Saudi Arabia, Similar pattern was recognized ( Hussain et al 2013 ) This figure is lower than that found in The Republic of Yemen (21\%). (Al-Hureibi et al; 2004) Our finding further coincides with the study carried out in Riyadh (Alghamdi. Et al ; 2014)

Thyroid nodule presenting as either a solitary nodule or a multinodular goiter (Mazzaferri; 2004). Most of thyroid nodules are more common in women. One or more palpable thyroid nodules affect $4 \%$ of the adult population; most of these nodules are benign (Rossi; 2006). Majority of solitary nodules of the thyroid proved to be localized, non-neoplastic conditions (Mazzaferri; 2004). Likewise, our results confirmed this fact as most of our patients with solitary nodules were found negative for malignancy.

In the present study, it was found that the cancer was more more frequent in males $(75 \%)$ than females $(25 \%)$. Similar results were obtained by (Hussein et al 2013). Considerable geographical variations were present in thyroid cancer incidence in Saudi Arabia.(Bazarbashi et al ; 2008)

In the present study, most of the patients with hyperthyroidism were complaining of palpitation $(87.7 \%)$ and tremors $(63.2 \%)$. 


\section{International Journal of Science and Research (IJSR) \\ ISSN (Online): 2319-7064 \\ Index Copernicus Value (2013): 6.14 | Impact Factor (2014): 5.611}

About half of the case ( $49.1 \%$ ) had weight loss and (35.1\%) had sweating .Others had exophthalmos, goiter , exophthalmos and irritability .Similarly symptoms recorded by (Michelageli et al ,200 ) were palpitation, tremors and weight loss each were over $50 \%$. Other symptoms recorded included excessive sweating (45\%), heat intolerance (31\%), and nervousness (27\%). On the hand, exophthalmos, tremors, and tachycardia ranked top on the list of clinical signs representing over $40 \%$ for each. However they added clinical manifestation that not included in the present work which were Proximal myopathy ( $8 \%$ ) and atrial fibrillation (4\%) of patients. Graves' ophthalmopathy in their study was noted in $54 \%$ of their patients.

\section{Conclusion}

Thyroid disorders are common in Hail region specially in females. The pattern is more or less similar to that detected in other Saudi cities. Goiter and malignant thyroid are more common in males .

\section{Recommendation}

More studies should be carried out in Hail region to stress on the individual thyroid disorder so as more comprehensive studies could be obtained.

\section{Limitation of the Study}

This hospital-based retrospective study, included those attended the king Khalid hospital only . To represent Hail region as a whole, the study should extend to cover more areas of hail region specially the remote villages .

\section{Acknowledgment}

We would like to thank dctor Ashraf Negm, the head deparment of endocrinology for his continuous help and support to get the patients' files an registries .

\section{References}

[1] Abdul Rahman Al-Nuaim, MB, FRCP(C), FACP; Yagob Al-Mazrou, MB, PhD, FRCGP; Mohammed Kamel, MB, MD Omer Al-Attas, PhD; Nasser AlDaghari, MSc; RiyadSulimani, MB, FRCP(C), FAC IODINE DEFICIENCY IN SAUDI ARABIA Ann Saudi Med 1997;17(3):293-297.

[2] Abdul Shakoor SA1, Hawkins R, Kua SY, Ching ME, Dalan R. Natural history and comorbidities of subjects with subclinical hyperthyroidism: analysis at a tertiary hospital setting. Ann Acad Med Singapore. 2014 Oct;43(10):506-10.

[3] Abu-Eshy, S.A.,Al-Shehri, M.Y.,Khan,A.,Khan, G.M.,Al- Humidi, M.A., Maltani, T.S. (1994): Causes of goiter in the Asir region: a histopathological analysis of 361 cases.Ann Saudi Med.11:285-288.

[4] AL Bouq,Y., Fazili ,F.M., Gaffar,H.A. (2006): The Current Pattern of Surgically treated Thyroid diseases in the Medinah region of Saudi Arabia. JK-Practitioner, 13(1):9-14 Ozean Journal of Applied Sciences 1(1), 2008.
[5] Akbar DH, Ahmed MM, Al-Mughles J. Thyroid dysfunction and thyroid autoimmunity in Saudi type 2 diabetics. ActaDiabetol 2006;43:14e8.

[6] Alghamdi IG1, Hussain II, Alghamdi MS, Dohal AA, Almalki SS, El-Sheemy MAJ Immigr Minor Health. The Incidence Rate of Thyroid Cancer Among Women in Saudi Arabia: An Observational Descriptive Epidemiological Analysis of Data from Saudi Cancer Registry 2001-2008. 2014 May 25. [Epub ahead of print].

[7] Al-Hureibi KA, Abdulmughni YA, AlHureibi MA, AlHureibi YA, Ghafoor MA. The epidemiology, pathology, and management of thyroid cancer in Yemen. Ann Saudi Med 2004 March;24(2):119-.

[8] Al-Tameem MM. (1987): The pattern of surgically treated thyroid disease in two general hospitals in Riyadh. Saudi Med J,8:61-66.

[9] Alzahrani,A.S., Aldasouqi,S., Abdel Salam,S., Sultan, A.(2005): Autoimmune thyroid disease with fluctuating thyroid function.PLOS Med.2:401-403

[10] Bazarbashi S. Saudi Cancer Registry. Cancer Incidence Report 2004. Riyahd (KSA): Saudi Cancer Registry; 2008. p. 1-98.

[11]Belfiore A, LaRosa GL, LaPorta GA, (1992): Cancer risk in patients with cold thyroid nodules: relevance of iodine intake, sex, age, and multinodularity. Am J Med .93:363-369.

[12] Dodd NS and Samuel AM.(1993): Iodine deficiency in adolescents from Bombay slums. Natl Med J India,6(3):110-113.

[13]Elahi S, Manzoor-ul-Hassan A, Syed Z, Nazeer L, Nagra SA and Hyder SW (2005): A study of goiter among female adolescents referred to centre for nuclear medicine, Lahore. Pak J Med Sci. 21(1): 56- 62.

[14]El-May MV, Bourdoux P, Ben SF, Ben AM, Mtimet S.(1997): Fairly elevated incidence of goiters with marginally low urinary iodine in adolescents living in the northwestern part of Tunisia. Eur J Epidemiol, 13(3):363-365.

[15] Flynn R. W. V., T. M. MacDonald, A. D. Morris, R. T. Jung, and G. P. Leese, "The thyroid epidemiology, audit, and research study: thyroid dysfunction in the general population," Journal of Clinical Endocrinology and Metabolism, vol. 89, no. 8, pp. 3879-3884, 2004. View at Publisher • View at Google Scholar • View at Scopus.

[16] Griffith, R.W.(1999): Thyroid conditions in older patients. Practitioner,243: 214-221. Nasr HA. (1983): Surgically treated goiter at King Abdulaziz University Hospital, Jeddah , Saudi Arabia ,8th Saudi Medical Conference, 1983 (Abstracts). King Khalid Academy, Riyadh, P.78.

[17]Hanna CE and LaFranchi SH.(2002): Adolescent thyroid disorders. AdolescMed, 13:13-35.

[18] Hussain F1, Iqbal S, Mehmood A, Bazarbashi S, ElHassan T, ChaudhriN.HematolOncol Stem Cell Ther. .Incidence of thyroid cancer in the Kingdom of Saudi Arabia, 2000-2010. 2013 Jun;6(2):58-64. doi: 10.1016/j.hemonc.2013.05.004. Epub 2013 Jun 10.

[19] Knudsen N, Bulow I, Jorgensen T, Laurberg P, Ovesen L and Perrild H.(2000): Comparative study of thyroid function and types of thyroid dysfunction in two areas 


\section{International Journal of Science and Research (IJSR) \\ ISSN (Online): 2319-7064}

Index Copernicus Value (2013): 6.14 | Impact Factor (2014): 5.611

in Denmark with slightly different iodine status. Eur J Endocrinol , 143: 485-491.

[20] Koriech OM, Al Kuhaymi R.( 1988) :Thyroid cancer: clinicopathological study of 113 cases In Saudi Arabia. Saudi Med J;9:188-193.

[21] Koutras DA.(2001): Thyroid nodules in children and adolescents: consequences in adult life. J PediatrEndocrinolMetab , 14 (Suppl 5):1283-1287.

[22]LaFranchi S.(1994): Adolescent thyroid disorders. AdolescMed , 5(1):65-86.Memonab, A.(2004): Family history of benign thyroid disease and cancer and risk of thyroid cancer.Eur.J. Cancer40:754-760.

[23] Maitra A, Abbas AK. The endocrine system. In, Kumar $\mathrm{V}$, Abbas AK, Fausto N. Robbins and Cotran, Pathologic basis of disease.7th ed Elsevier Saunders 2005. ch:24, 1155 -1226. 2008.

[24] Martin I Surks, MD Clinical manifestations of hypothyroidism Aug 13, 2013.

[25] Mazzaferri; 2004 Thyroid Cancer in Thyroid Nodules: Finding a Needle in the Haystack," The American Journal of Medicine, Vol. 93, No. 4, 1992, pp. 359-362. doi:10.1016/0002-9343(92)90163-6.

[26] Michelageli VP, Pawape G, Sinha A, Ongugu K, Linge $\mathrm{D}$, Sengupta $\mathrm{SH}$, et al. Clinical features and pathogenesis of thyrotoxicosis in adult Melanesians in Papua New Guinea. ClinEndocrinol (Oxf) 2000; 52: 261-6.

[27] Morganti S, Ceda GP, Saccani M et al Thyroid disease in the elderly: sex-related differences in clinical expression. J Endocrinol Invest 2005;28(11 Suppl Proceedings):101-4.

[28] National Cancer Registry. Cancer incidence report Saudi Arabia 1997-1998. National Cancer Registry 2001: 28-9

[29] Ordookhani A, Mirmiran P, Najafi R, Hedayati M, Azizi F.( 2003): Congenital hypothyroidism in Iran. Indian J Pediatr.; 70(8):625-628.

[30] Rallison ML, Dobyns BM, Meikle AW, Bishop M, Lyon JL, Stevens W.(1991): Natural history of thyroid abnormalities: prevalence, incidence and regression of thyroid diseases in adolescents and young adults. Am J Med ,91(4):363-370.

[31]Rossi ED, Raffaelli M, Mule, A et al Simultaneous immunohistochemical expression of HBME-1 and galectin-3 differentiates papillary carcinomas from hyperfunctioning thyroid nodule of the thyroid. Histopathology 2006 June;48(7):795-800.

[32] Rossi RL, Nieroda C, Cady B, Wool MS. (1985): Malignancies of the thyroid gland in the Lahey Clinic experience. SurgClin N Am ;65:211-229.

[33] Sulimani RA, Al-Attas OS, Ali ME, El-Desouki M, AlNuaim AA, Al-Sekait MA.(1995): The prevalence of endemic goiters among schoolchildren and adolescents in Gizan, Saudi Arabia. Saudi Med J.,16(4):291-293.

[34] Takasu N, Yamada T, Sato A, Nakagawa M, Komiya I. (1990): Graves'disease following hypothyroidism due to Hashimoto's disease: Studies of eight cases. ClinEndocrinol (Oxf) 33: 687-698

[35] Wintergerst K, Gembel G, Kreipe T, Zeller P, Eugster E, Young B, Andruszewski K, Kleyn M, Cunningham T, Fawbush S, Vanderburg N, Sockalosky J, Menon R, Linard S, Hoffman G, Gorman L Congenital Hypothyroidism Long-Term Follow-up Project:
Navigating the Rough Waters of a Multi-Center, MultiState Public Health Project. J Genet Couns.2014 Nov 18 . 